The Mental Health of Latinx Adults in the United States During the Coronavirus Pandemic: A Snapshot of Anxiety, Depression, and Posttraumatic Stress Symptoms

\author{
Bianca T. Villalobos ${ }^{1}$ (D) http://orcid.org/0000-0002-7191-9757 \\ Juventino Hernandez Rodriguez (iD http://orcid.org/0000-0003-2311-4687 \\ Department of Psychological Science, The University of Texas Rio Grande Valley
}

${ }^{1}$ Correspondence concerning this article should be addressed to Bianca T. Villalobos, Ph.D., Department of Psychological Science, The University of Texas Rio Grande Valley, 1201 W. University Dr., Edinburg, Texas 78539. Phone: 956-665-7961, Email: bianca.villalobos@utrgv.edu 


\begin{abstract}
Objective: The current study documented levels of anxiety, depression, posttraumatic stress, and COVID-19 fears and impacts among Latinxs in the U.S. during the COVID-19 pandemic.

Method: Participants of this cross-sectional study were 388 Latinx adults who completed an online survey between June and November 2020.

Results: Almost half of participants showed clinical levels of anxiety and depression and more than a quarter of participants showed clinical levels of posttraumatic stress. Latinxs reported on average 22 types of negative pandemic life impacts. Group differences based on gender, educational attainment, income, vulnerability to COVID-19, and essential worker status were found for mental health symptoms. Severity of COVID-19 fears and negative life impact counts were related to gender, nativity, educational attainment, vulnerability to COVID-19, and insurance status.
\end{abstract}

Conclusion: Specific Latinx groups experienced greater levels of psychological distress during the pandemic. Further examination of risk and protective factors is needed for communities of color.

Keywords: COVID-19, Latinx, anxiety, depression, posttraumatic stress 


\section{The Mental Health of Latinx Adults in the United States During the Coronavirus \\ Pandemic: A Snapshot of Anxiety, Depression, and Posttraumatic Stress Symptoms}

The coronavirus (COVID-19) pandemic has changed the lives of people all over the world in regard to their employment, interpersonal interactions, and home life. Subsequently, these life changes have resulted in additional stressors and heightened levels of mental health symptoms for communities of color in the United States (U.S.). However, empirical data on the mental health status of Latinx communities during the COVID-19 pandemic is limited. The purpose of this study is to obtain a snapshot of the mental health status of U.S. Latinx adults. We examine prevalence rates of anxiety, depression, and posttraumatic stress (PTS) symptomology, the severity and impairment of COVID-19 fears, and COVID-19-related life impacts. We also examine whether mental health symptoms and COVID-19 fears and impacts varied by specific psychosocial demographic variables.

As of December 30, 2020, COVID-19 has infected over 82 million across the world, with the U.S. surpassing all other countries in confirmed cases (19.5 million) and deaths (over 338,000; Dong et al., 2020). Emerging evidence suggest that Latinxs, among other communities of color, are disproportionally impacted by the COVID-19 pandemic. The Color of Coronavirus Project, an ongoing study that examines U.S. COVID-19-related deaths by race and ethnicity, found that the age-adjusted mortality rates for Latinxs are three times higher than for non-Latinx Whites (American Public Media Research Lab, 2020). In addition to higher mortality rates, preexisting inequities in social determinants of health exacerbate the impact of the pandemic and its sequalae on Latinxs (Fortuna et al., 2020). For example, pre-pandemic Latinxs had lower wages, lower income, and less access to employment benefits and health care compared to nonLatinx Whites (Gould et al., 2020). These standing disparities highlight the current economic 
realities faced by almost half of Latinxs (49\%), who report they or someone in their household had a reduction in pay or lost their job due to the pandemic (Krogstad et al., 2020). Moreover, risk of exposure to the virus might be higher for Latinxs because, compared to non-Latinx Whites, they are less likely to hold positions that give them the option of working from home (Gould et al., 2020).

Furthermore, health disparities have been well documented for Latinxs living with chronic health conditions such as diabetes mellitus, cancer, and cardiovascular disease (VelascoMondragon et al., 2016). These same health conditions place Latinxs at increased risk for severe illness after contracting COVID-19 (Center for Disease Control and Prevention [CDC], 2020). In addition to low-income and medically compromised populations, Latinx parents and immigrants may be disproportionately impacted by pandemic-related stressors (Clark et al., 2020; Fortuna et al., 2020). For instance, Brown et al. (2020) found that compared to Black parents, Latinx parents reported more disruptions across several domains (e.g., parent and child physical health, parent-child relationship, parent mood or stress) as a result of the COVID-19 pandemic and mitigation efforts. Undocumented Latinx immigrants and asylum seekers in the U.S. are at particular risk of mental health consequences due to their histories of traumatic stress coupled with poor conditions at shelters and detention centers, anti-immigration policies, and lack of access to mental health care (Garcini et al., 2020). Indeed, Latinxs and other communities of color report more worry than non-Latinx Whites about contracting the virus, accessing basic needs, and barriers to health care (American Psychological Association, 2020). These worries are justified given the economic and health disparities experienced by Latinxs, as well as barriers accessing healthcare services (Fortuna et al., 2020; Lund, 2020; Thakur et al., 2020). Researchers have documented a number of structural and attitudinal barriers (e.g., lack of health insurance 
stigma, mistrust of providers, cost of services, lack of bilingual providers) that result in Latinxs' general underutilization of mental health services compared to non-Latinx Whites (Falgas et al., 2017). It is possible that these and other risk factors impact Latinxs' mental health status and ability to cope during the COVID-19 pandemic.

The empirical data available on the impact of the COVID-19 pandemic on the mental health of community samples in the U.S. is very limited. Holingue et al. (2020) surveyed a nationally representative online sample of adults without a preexisting psychiatric disorder at the outset of the pandemic in March 2020. Using a five-item screening measure, results revealed the most common symptom reported was anxiety (39\%), followed by trouble sleeping $(27 \%)$, depression (19\%), loneliness (15\%), and hyperarousal (5\%). Although the study provided an overview of psychological distress during the COVID-19 pandemic, it is unclear whether individuals exhibited any mental health symptoms, including subclinical levels, prior to the pandemic. Two independent studies compared online nationally representative samples from April 2020 to data collected from adults who participated in the National Health Interview Survey in 2018 (McGinty et al., 2020; Twenge \& Joiner, 2020). Results from both studies revealed that the proportion of U.S. adults with "serious psychological distress" was significantly higher in 2020 during the pandemic (13.6-27.7\%) than in 2018 (3.4-3.9\%). Lastly, C. H. Liu et al. (2020) assessed mental health conditions using disorder-specific screening measures with a sample of 898 young adults in April 2020. They found clinically elevated levels of depression (43.3\%), anxiety (45.4\%), and posttraumatic stress disorder (PTSD) symptoms $(31.8 \%)$ in the sample. Although several of these studies used nationally representative samples to examine the mental health impact of the COVID-19 pandemic on adults (e.g., Holingue et al., 2020; McGinty et al., 2020; Twenge \& Joiner, 2020), they are limited in their ability to describe Latinx-specific 
responses to the pandemic. For example, Latinx ethnicity was a protective factor against psychological distress in the study by Holingue et al. (2020), while it was a risk factor in the study by McGinty et al. (2020). Though these findings can help us understand how Latinxs' psychological distress compares to the general population, additional studies are needed to uncover disparities in the mental health impact of the pandemic on the at-risk groups previously described (i.e., low-SES, immigrants, vulnerable to severe illness, etc.). To our knowledge, there have been no published studies that have focused exclusively on Latinx mental health during the COVID-19 pandemic and whether the impact has been uniform across demographic groups.

The purpose of this study is to address the need for more research on ethnic and racial minorities by providing preliminary descriptive information about the frequency and severity of psychological distress among Latinxs during the COVID-19 pandemic. The specific aims of the current study were (1) to report prevalence rates of anxiety, depression, PTS, illness and virus fears, and life changes during the pandemic, and (2) to identify demographic characteristics related to the aforementioned mental health symptoms, illness and virus fears, and life changes.

\section{Method}

\section{Procedure}

The study was posted online via Qualtrics as an anonymous online survey and was available in Spanish and English. Participants were eligible if they were at least 18 years of age, resided in the U.S., and identified as Latinx, Latina, Latino, or Hispanic. Participants were recruited through social media (e.g., Twitter, Facebook), psychology-related listservs, and university e-mails sent to students, faculty, and staff. Data collection lasted approximately four months (June 24, 2020-November 2, 2020), and surveys took approximately 30 minutes to complete. Throughout the survey, participants were given the option to skip any questions that 
they did not want to answer and proceed with the study. Participants who finished the survey were given the option to enter a raffle to win one of $20 \$ 25$ gift cards. A total of 445 participants accessed and provided responses to the online survey. For the current study, the analytical sample was a subset of 388 participants for whom a total score or subscale score could be computed on at least one of the dependent variables. All procedures were approved by the Institutional Review Board at The University of Texas Rio Grande Valley.

\section{Measures}

In addition to demographic information, participants completed a variety of mental health screening questionnaires and newly developed COVID-19 measures. Participants were also asked to indicate whether they or an individual living in the home was an essential worked or vulnerable to COVID-19. In regard to essential worker status, this term was defined for participants using the U.S. Department of Homeland Security Cybersecurity and Infrastructure Security Agency's (CISA) list of essential work sectors (Version 1.0; issued March 2020):

Health care employees, first responders, food and agriculture employees, energy employees, water and sanitation, transportation and logistics, public workers, manufacturing, communications and information technology, community-based government operations and essential functions, financial services, hazardous material management, defense industrial base, and chemical management employees.

In this study, vulnerability to COVID-19 was defined using the CDC's initial list of populations at high risk for severe illness from the virus, which was expanded in June 2020 to include other groups not listed here:

People aged 65 and older, people living in a nursing home or long-term care facility, people with chronic lung disease or moderate to severe asthma, people with serious heart 
conditions, people who are immunocompromised, people with severe obesity, people with diabetes, people with chronic kidney disease undergoing dialysis, and people with liver disease.

\section{Anxiety and Depression}

Patient Health Questionnaire (PHQ) modules on anxiety (Generalized Anxiety Disorder 7-item Scale [GAD-7]; Spitzer et al., 2006) and depression (PHQ 9-item Scale [PHQ-9];

Kroenke et al., 2001) were used to assess anxiety and depression symptom severity. Items from the GAD-7 and PHQ-9 were developed based on the DSM-IV, but closely follow existing diagnostic criteria from DSM-5 criteria. Participants respond to items by indicating the frequency that they have been bothered by the items in the prior two weeks on a Likert scale from 0 (Not at all) to 3 (Nearly every day). Recommended cut points for total severity scores on the PHQ-9 distinguish between those with mild (5), moderate (10), moderately severe (15), and severe (20) depression. Severity cut points for mild, moderate, and severe anxiety on the GAD-7 are 5, 10, and 15, respectively. For both the GAD-7 and PHQ-9, scores of 10 or higher suggest a clinical diagnosis might be warranted, whereas scores of 15 or higher suggest clinical intervention is warranted (Kroenke et al., 2001; Spitzer et al., 2006).

A study examining the psychometric properties of the GAD-7 with a sizable Latinx community sample reported excellent internal consistency $(\alpha=.93)$ for the overall sample, high reliability for English $(\alpha=.91)$ and Spanish $(\alpha=.94)$ language-preference groups, and convergent validity with a measure of perceived stress (Mills et al., 2014). Similarly, studies examining the PHQ-9 with Latinx adults reported strong psychometric properties, with good internal consistency ( $\alpha=.84-.85$ ) and construct validity (Huang et al., 2006; Merz et al., 2011). In this study, internal consistency was excellent for the PHQ-9 $(\alpha=.92)$ and GAD-7 $(\alpha=.95)$. 


\section{Posttraumatic Stress}

The PTSD Checklist for DSM-5 (PCL-5; Weathers et al., 2013) is a 20-item self-report measure that assesses PTS symptoms. Participants are asked how often they have been bothered by each symptom in the last month. Items are scored from 0 (Not at all) to 4 (Extremely). Subscale severity scores that correspond to DSM-5 PTSD symptom clusters can be calculated, as well as a total severity score. A cut-point of 31 to 33 can be used to determine a provisional diagnosis of PTSD and a referral to PTSD treatment. Previous studies have reported strong psychometric properties for the PCL (Blevins et al., 2015; Bovin et al., 2016).

For purposes of this study, we adapted the PCL-5 to specifically ask participants about symptoms in response to the COVID-19 pandemic. Items with the words "stressful experience" were adapted to state "coronavirus" to directly assess reactions to the pandemic. This procedure was similarly done in other studies that have used the PCL-5 in pandemic-related research (e.g.,

N. Liu et al., 2020). In the current study, the total severity score was used in analyses and had an excellent internal consistency $(\alpha=.94)$.

\section{COVID-19 Fears}

The Fear of Illness and Virus Evaluation (FIVE; Ehrenreich-May, 2020) is a newly developed 35-item self-report measure that assesses COVID-19 pandemic fears. The measure reports on four provisional subscales: fears about contamination and illness (9 items), fears about social distancing (9 items), behaviors related to illness and virus fears (13 items), and impact of illness and virus fears ( 2 items). The first two subscales are scored from 1 (I am not afraid of this at all) to 4 (I am afraid of this all of the time). The behavior subscale is scored from 1 (I have not done this in the last week) to 4 (I did this all the time last week). Lastly, the two impact items are scored from 1 (Not true for me at all) to 4 (Definitely true). A composite score can be calculated 
by summing all items except those on the subscale for behaviors related to illness and virus fears. Because the FIVE was developed during the COVID-19 pandemic, psychometric properties are not yet available.

In this study, internal consistency was excellent for fears related to contamination and illness $(\alpha=.92)$, fears related to social distancing $(\alpha=.91)$, and the composite score $(\alpha=.94)$. Internal consistency for the subscales of behaviors related to illness and virus fears $(\alpha=.73)$ and impact ( $\alpha=.82$ ) was acceptable and good, respectively. All four subscales and the composite score were used in analyses.

\section{COVID-19 Impacts}

COVID-19 pandemic impacts were measured with the 92-item Epidemic-Pandemic Impacts Inventory (EPII; Grasso et al., 2020). Participants were asked to identify ways in which the pandemic has impacted various aspects of their life and the lives of people in their home. The measure assesses 10 domains of impact: work and employment (11 items), education and training (2 items), home life (13 items), social activities (10 items), economic (5 items), emotional health and well-being ( 8 items), physical health problems ( 8 items), physical distancing and quarantine (8 items), infection history (8 items), and positive change (19 items). For each item, participants were provided the following response options: "Yes, Me," "Yes, Person in Home," "No," and "Not Applicable." In this study, we collapsed participants' first two responses (i.e., "Yes, Me" or "Yes, Person in Home") into one category and combined the last two responses (i.e., "No" or "Not Applicable") into another category. A cumulative negative change score was calculated by summing all domains with the exception of the positive change domain. The cumulative negative change score and the positive change domain were used in analyses. 


\section{Statistical Analyses}

Statistical analyses were performed using IBM SPSS, Version 26. A series of independent-samples $t$-tests and one-way ANOVAs were conducted to examine whether mental health variables (anxiety, depression, and PTS severity) and COVID-19 related variables (impacts and fears) differed by participant demographic variables: gender, language, nativity, education level, employment status, essential worker in household, vulnerable person in household, income, insurance status. Welch's $F$-test is reported for all ANOVAs and post-hoc comparisons were computed using the Games-Howell correction. Bivariate and point-biserial correlations were conducted to examine the relations among all study variables (see Supplementary Table 1).

\section{Results}

\section{Missing Data}

Missing data for the dependent variables varied: $0.3-5.9 \%$ for the EPII subscales; $10.3-$ $12.1 \%$ for the FIVE subscales; $12.4 \%$ for the GAD-7; $13.1 \%$ for the PHQ-9; $14.9 \%$ for the PCL5. Approximately $21 \%$ of participants did not provide a valid response to an item about race. A majority of these individuals instead reported their ethnicity or nationality, which was already captured by the inclusion criteria of the survey (e.g., "Hispanic," Chicana," and "MexicanAmerican"). Thus, race was not included in analyses with outcome measures. All other demographic variables had less than $4.0 \%$ missing data.

\section{Demographic Characteristics of the Sample}

Participant demographics are provided in Table 1. Of the 388 participants, the majority identified as female (82.0\%), White (91.6\%), U.S.-born (83.7\%), and single $(63.9 \%)$. The average age was 28.52 years $($ range $=18-69)$. Most participants lived in Texas $(87.9 \%)$, 
followed by California (7.2\%). Of those from Texas, $80.3 \%(n=312)$ were from four counties in the lower Rio Grande Valley, near the U.S.-Mexico border. The majority of participants reported English was their primary language (78.4\%), had at least a college degree (59.0\%), an annual household income of at least $\$ 40,000$ (56.0\%), and were insured (66.3\%). Regarding employment status, $42.8 \%$ were students and $34.8 \%$ worked full-time. In addition, $65.4 \%$ indicated they or someone in the home was an essential worker, and $57.7 \%$ indicated they or someone in the home was vulnerable to COVID-19. On average, participants reported approximately four people living in their household.

\section{Descriptive Statistics on Mental Health and COVID-19 Variables}

See Table 2 for means, standard deviations, and percentages for each of the mental health and COVID-19 measures. Utilizing recommended cut-points for the GAD-7 and PHQ-9 (scores $\geq 10), 48.9 \%$ and $47.8 \%$ of participants reported moderate to severe anxiety and depression, respectively. After examination of scores at or above the cut-point of 15, more than a quarter of individuals would benefit from active psychotherapy treatment for symptoms of anxiety (27.1\%) and depression (26.4\%). Lastly, using the PCL-5's recommended cut-point of 31, 26.1\% of participants demonstrated PTS symptoms congruent with a provisional diagnosis of PTSD.

Participants also reported on their own fears related to the virus, social distancing, safety behaviors, and impairment related to the coronavirus (Table 2). Participants reported on average 22 negative impacts and 9 positive changes since the coronavirus pandemic began (see Table 3

for the most common impacts reported). The most common negative impacts included spending more time on screens and devices, more time sitting down or being sedentary, and family celebrations getting cancelled or restricted. The most common positive changes reported 
included being more appreciative of things usually taken for granted, paying more attention to one's personal health, and more quality time with family or friends in person or from a distance.

\section{Demographic Characteristics Associated with Mental Health Symptom Severity}

See Table 4 for mental health measure means by demographic variables. Compared to males, females had significantly higher average anxiety, $t(331)=-3.46, p=.001, d=0.51$, depression, $t(328)=-3.35, p=.001, d=0.50$, and PTS scores, $t(321)=-3.24, p=.001, d=$ 0.48. Those whose primary language was Spanish had significantly higher depression, $t(331)=$ $2.50, p=.013, d=0.34$, and PTS mean scores, $t(324)=2.49, p=.013, d=0.34$. Analyses revealed a statistically significant group difference in depression, $F(2,62.88)=16.86, p<.001$, and PTS mean scores, $F(2,59.73)=3.83, p=.027$, by participant marital status. Single participants had higher average depression $(p<.001, d=1.12)$ and PTS scores $(p=.027, d=$ 0.31) compared to those who were married or cohabitating. Analyses revealed a statistically significant group difference in mean anxiety, $F(2,152.97)=4.79, p=.01$, depression, $F(2$, $160.57)=9.66, p<.001$, and PTS scores, $F(2,156.23)=7.55, p=.001$, by participant educational attainment. Compared to those with graduate or professional degrees, participants with less than a college level of education reported higher mean anxiety $(p=.016, d=0.47)$, depression $(p<.001, d=0.55)$, PTS scores $(p=.004, d=0.56)$. Similar findings were found between Latinxs with graduate degrees and those with undergraduate degrees (anxiety: $p=.012$, $d=0.44$; depression: $p=.001, d=0.63$; PTS: $p=.001, d=0.51$. There was a statistically significant group difference based on employment status, $F(2,96.95)=8.11, p<.001$, such that participants who worked full-time had lower mean depression scores compared to students $(p<$ $.001, d=0.57)$ and those not working $(p=.02, d=0.54)$. 
Participants who had an essential worker living in the home had statistically significant higher average anxiety, $t(332)=-2.84, p=.005, d=0.33$, depression, $t(329)=-2.63, p=.009, d$ $=0.30$, and PTS scores, $t(322)=-2.49, p=.013, d=0.29$, compared to those without an essential worker in the home. Participants who had a person vulnerable to COVID-19 living in the home had statistically significant higher average anxiety, $t(335)=-2.64, p=.009, d=0.29$, depression, $t(333)=-2.01, p=.046, d=0.22$, and PTS scores, $t(326)=-2.51, p=.012, d=0.28$, compared to those who did not have a vulnerable person at home. Statistically significant group differences were found based on annual household income: anxiety, $F(2,184.65)=4.44, p=.013$, depression, $F(2,189.85)=11.57, p<.001$, and PTS, $F(2,183.69)=4.30, p=.015$. Those with incomes higher than $\$ 80,000$ had lower average anxiety $(p=.014, d=0.41)$, depression $(p<$ $.001, d=0.66)$, and PTS scores $(p=.011, d=0.41)$ compared to those with incomes below $\$ 40,000$. Uninsured participants had significantly higher average depression scores compared to those with health insurance, $t(331)=3.61, p<.001, d=0.42$.

\section{Demographic Characteristics Associated with COVID-19 Fears}

See Table 5 for means scores on the FIVE subscales and composite score by demographic variables. Female participants had statistically significant higher mean scores on all four subscales and the composite score compared to males: Fears about Contamination and Illness, $t(339)=-3.19, p=.002, d=0.46$; Fears about Social Distancing, $t(334)=-2.37, p=.018$, $d=0.35$; Behaviors Related to Illness and Virus Fears, $t(332)=-3.62, p<.001, d=0.53$; Impact of Illness and Virus Fears, $t(332)=-2.93, p=.004, d=0.43$; and Composite, $t(334)=-3.14, p=$ $.002, d=0.46$. U.S.-born participants had statistically significant higher mean scores compared to those born outside the United States on two FIVE subscales and the composite score: Fears about Contamination and Illness, $t(345)=-1.99, p=.047, d=0.30$; Impact of Illness and Virus 
Fears, $t(339)=-2.66, p=.008, d=0.40$; and Composite, $t(341)=-2.34, p=.02, d=0.35$.

Marital status was associated with mean scores on the Fears about Social Distancing subscale, $F(2,63.76)=4.85, p=.01$, and Composite score, $F(2,62.22)=3.88, p=.026$. Post-hoc comparisons showed that single participants had statistically significant higher mean scores on the Fears about Social Distancing subscale $(p=.006, d=0.37)$ and Composite score $(p=.015, d$ $=0.33$ ) compared to married or cohabitating participants. Analyses revealed statistically significant group differences based on participant educational attainment for all but the Behaviors Related to Virus Fears subscale: Fears about Contamination and Illness, $F(2,168.80)$ $=6.32, p=.002$; Fears about Social Distancing, $F(2,159.36)=8.26, p<.001$; Impact of Illness and Virus Fears, $F(2,150.83)=-2.93, p=.027$; and Composite, $F(2,160.36)=8.34, p<.001$. Post-hoc comparisons showed participants with graduate degrees, compared to those with undergraduate degrees, reported lower scores on the FIVE Fears about Contamination and Illness $(p=.003, d=0.49)$, Fears about Social Distancing $(p<.001, d=0.61)$, Impact of Illness and Virus Fears $(p=.04, d=0.39)$ and Composite $(p<.001, d=0.60)$. Similarly, participants with graduate degrees, compared to those who did not have college schooling, reported lower scores on the FIVE Fears about Contamination and Illness $(p=.01, d=0.41)$, Fears about Social Distancing $(p=.006, d=0.47)$, Impact of Illness and Virus Fears $(p=.03, d=0.43)$ and Composite $(p=.004, d=0.49)$.

Participants who identified as vulnerable to COVID-19 had statistically significant higher mean scores compared to those who were not vulnerable to COVID-19 on three subscales and the composite score of the FIVE: Fears about Contamination and Illness, $t(343)=-3.81, p<$ $.001, d=0.42 ;$ Fears about Social Distancing, $t(338)=-3.27, p=.001, d=0.36$; Impact of Illness and Virus Fears, $t(336)=-2.96, p=.003, d=0.33$; and Composite, $t(338)=-3.91, p<$ 
$.001, d=0.43$. Analyses also revealed a statistically significant group difference in FIVE scores by annual household income: Fears about Social Distancing, $F(2,192.71)=8.59, p<.001$; Impact of Illness and Virus Fears, $F(2,185.21)=4.10, p=.018$; and Composite, $F(2,192.99)=$ $6.91, p=.001$. Participants with incomes higher than $\$ 80,000$, compared to those who with incomes below $\$ 40,000$, had lower mean scores on the FIVE Fears about Social Distancing subscale $(p<.001, d=.54)$, Impact of Illness and Virus Fears subscale $(p=.014, d=.40)$, and Composite score $(p=.001, d=.50)$. Regarding insurance status, participants who were insured had statistically significant higher mean scores compared to those without health insurance on the Fears of Social Distancing subscale, $t(339)=3.76, p<.001, d=.44$, and Composite score, $t(339)=2.50, p=.013, d=.29$.

\section{Demographic Characteristics Associated with Positive and Negative COVID-19}

See Table 6 for count scores on the Positive Changes and Negative Impacts subscales of the EPII by demographic groups. Individual t-tests showed males reported significantly more positive changes, $t(356)=2.32, p=.021, d=.33$, and fewer negative impacts, $t(370)=-3.94, p<$ $.001, d=.56$, compared to females. U.S.-born participants reported significantly more negative impacts than immigrant participants, $t(377)=-2.28, p=.023, d=.32$. There were statistically significant group differences based on level of education, $F(2,182.31)=8.27, p<.004$, such that individuals with graduate schooling experienced fewer negative impacts than those with undergraduate degrees $(p<.001, d=.56)$ and those without college degrees $(p=.005, d=.46)$. Participants who reported they had an essential worker or vulnerable person living in the home reported significantly more negative impacts than individuals who did not have an essential worker, $t(372)=-3.83, p<.001, d=.42$, or vulnerable person at home, $t(375)=-4.02, p<.001$, 
$d=.42$. Lastly, individuals without health insurance reported more negative impacts due to the pandemic compared to their insured counterparts, $t(376)=2.42, p=.016, d=.27$.

\section{Discussion}

To our knowledge, this study is the first to provide preliminary data on the mental health status of a Latinx sample in the U.S. following the announcement of COVID-19 as a national emergency and global pandemic. Results corroborate what many commentaries in the field have posited regarding the potential impact of COVID-19 on Latinxs (e.g., Fortuna et al., 2020; Lund, 2020; Thakur et al., 2020). Indeed, a considerable amount of Latinxs reported struggling with clinically significant symptoms of anxiety, depression, and PTS. Almost half of participants reported moderate to severe levels of distress related to anxiety (48.9\%) and depression (47.8\%). In addition, one in four individuals in this study met the clinical cutoff for a provisional diagnosis of PTSD (26.1\%), specifically in response to COVID-19 as an index trauma. Rates of mental health symptoms in this study are comparable to rates reported by C. H. Liu et al. (2020): anxiety (45.4\%; GAD-7 scores $\geq 10$ ), depression (43.3\%; PHQ-8 scores $\geq 10$ ), and PTSD (31.8\%; PCL-Civilian scores $\geq 45)$.

The current study also identified key demographic characteristics consistently associated with higher levels of anxiety, depression, and PTS symptom severity: female gender (including transgender females), educational attainment less than a graduate degree, essential worker status (or living with an essential worker), vulnerability to COVID-19 (or living with a person vulnerable to COVID-19), and an annual household income of less than $\$ 40,000$. Likewise, the number of positive and negative life changes, as well as the severity of COVID-19 fears (i.e., FIVE composite scores), varied by demographic groups: Latinxs who were female, U.S-born, vulnerable to COVID-19 (or living with a person vulnerable to COVID-19), uninsured, and had 
less than a graduate degree reported higher levels of COVID-19 fears and experienced more negative impacts compared to their counterparts.

Notably, females reported higher levels of psychological distress and COVID-19 fears, and more negative life impacts compared to males. On the other hand, males reported more positive life changes than females. It is possible that gender role norms and the greater burden of household responsibilities placed on Latinas contribute to experiences of distress and fewer positive life changes during the pandemic. For example, Latinas may be juggling multiple demanding roles that compound pandemic-related stress, such as being a primary caregiver for a child going to school remotely, caregiver for extended family members in multigenerational homes, worker, homemaker, and college student. Moreover, Latinas in particular had higher rates of unemployment immediately after the start of the pandemic given they were more likely to work in industries considered nonessential (Gould et al., 2020). Stress due to temporary or continued unemployment may have impacted Latinas mental health and heightened worries about loss of income for basic needs. Overall, Latinas need more support and resources to manage the psychological impact of the pandemic.

Our findings run contrary to expectations that immigrant communities are at higher risk of the medical, economic, legal, and social consequences of the pandemic (Clark et al., 2020). In this study, U.S.-born participants reported more COVID-19 fears and negative impacts, but did not report higher levels of mental health symptoms compared to foreign-born Latinxs. Interestingly, higher levels of depression and PTS were found for participants whose primary language was Spanish. Findings represent a potential discrepancy in mental health adjustment based on nativity and language. It is possible U.S.-born Latinxs' familiarity with the medical system in the U.S. and access to English-language resources helped them navigate the risk of 
virus exposure and access to treatment, explaining their lower rates of anxiety, depression and PTS symptoms compared to Spanish-speakers. Variables that may help elucidate these findings are acculturation and adherence to traditional Latinx cultural values. Immigrant Latinxs who are less acculturated may endorse stronger cultural values, such as fatalism and spiritualism, that could serve as protective factors against COVID-19 fears. For instance, placing one's life in the hands of a higher power may reduce worry about illness, but may also result in fewer preventative safety behaviors (i.e., wearing masks and social distancing).

Findings suggest single Latinxs and those with lower annual household incomes (below \$40,000) experience more severe COVID-19 fears, but not necessarily more negative impacts, compared to their higher income or partnered counterparts. Married couples have a safety net as they can rely on their partners for financial support if they experience job loss or illness. Upon further examination of the data, we found the majority of single individuals lived with parents (77.8\%) and had a person vulnerable to COVID-19 in the home (62.2\%). Therefore, it is possible that single individuals had more fears related to transmitting the virus to vulnerable older adults in the household. Likewise, Latinxs with lower incomes might report more fears about social distancing due to the potential loss of income resulting from sickness. Items on the Fears of Social Distancing subscale of the FIVE include fears of missing work, losing one's job, and not having enough money to pay bills or take care of family due to illness. These results are consistent with those found by Tull et al. (2020) in which income level was significantly associated with health anxiety and financial worry among U.S. adults under stay-at-home orders in March 2020. Ultimately, low-income and single Latinxs are at particular risk of impairment related to COVID-19 fears because they may have more to lose. In addition, negative life impacts were endorsed at higher rates for those with an essential worker living in the home, 
although their fears about COVID-19 were no different from their counterparts. Essential workers are placed at increased risk of contracting the virus given their employment in critical sectors of the workforce. Consequently, this group of Latinxs may, out of necessity, develop cognitive coping strategies that attenuate fears of COVID-19 in order to perform their job duties.

The findings of the current study should be considered in light of limitations. Given the purpose of the study was to provide a snapshot of the state of Latinxs' mental health during the COVID-19 pandemic, the results are limited by the cross-sectional design of the study. The severity and frequency of mental health symptoms may fluctuate with the country's containment of the spread of the virus, increased or laxed restrictions in social distancing, mandates on wearing masks, and resulting consequences (i.e., job loss, sickness or death in the family). Thus far, December 2020 has proven to be the worst month for recorded COVID-19 cases in the U.S., and it is possible the prevalence of mental health symptoms will rise accordingly. Second, data were primarily obtained from a convenience sample, which may limit generalizability due to participants self-selecting to complete the online survey. Ultimately, our results might reflect a group of individuals who are more concerned about their mental health and COVID-19's impact on their lives. Although data were collected from an online convenience sample, screening measures administered in the study were well-validated and included cut points to indicate a probable clinical diagnosis of depression, anxiety, and PTSD. Additionally, the sample consisted of mostly educated individuals with a scarcity of male and immigrant representation. Similarly, due to more concerted efforts to recruit participants from the research team's academic institution, the majority of participants were primarily of Mexican descent from Texas and may not represent the mental health adjustment of other Latinx subgroups in other parts of the country. The study also did not assess preexisting mental health symptoms or psychiatric 
diagnoses before the start of the pandemic, which makes it difficult to determine whether reported anxiety and depression symptoms represent an exacerbation of symptoms or are a direct result of the pandemic. Finally, the study utilized novel COVID-19 measures that have yet to be fully examined for their psychometric properties and require further validation with ethnically and linguistically diverse populations.

Future studies should employ longitudinal methods to analyze the long-term mental health impact of COVID-19 on Latinxs even after the virus is contained and vaccinations are distributed to vulnerable individuals and essential workers. Researchers can also identify whether other subgroups of Latinxs (e.g., South Americans, Puerto-Ricans) are more susceptible to psychological consequences of the virus. Also, once social distancing restrictions are lifted, or with the help of telehealth, it will be important for researchers and clinicians to assess mental health symptoms with this population using structured interviews. Given one in four individuals had a probable diagnosis of PTSD due to COVID-19, existing PTSD measures should now include the pandemic as a potential index trauma, as are natural disasters. Furthermore, high levels of COVID-19 fears and safety behaviors merit examination of other symptomology not examined in this study, such as the prevalence of obsessive-compulsive disorders and agoraphobia. Subsequent research on Latinxs should analyze rates of mental health service utilization and barriers to access to care during the coronavirus, including use of telemental health services for the treatment of anxiety, depression, and PTSD.

\section{Conclusion}

Over a period of three to seven months after shelter-in-place orders were announced in the U.S., Latinxs in this study reported numerous negative changes in several life domains (e.g., employment, home life, social activities, emotional wellness, and physical health). Indeed, our 
study found a substantial proportion of individuals reported high levels of anxiety, depression, and PTS that would warrant treatment. Despite limitations, this study has provided preliminary evidence of psychological distress among Latinxs during the COVID-19 pandemic and highlighted potential risk factors for further examination. Future studies are needed to track subsequent changes in mental health during and after the pandemic in connection to variables that are known to contribute to mental health disparities for people of color. 


\section{References}

American Psychological Association. (2020). Stress in the Time of COVID-19 https://www.apa.org/news/press/releases/stress/2020/stress-in-america-covid.pdf American Public Media Research Lab. (2020). The Color of Coronavirus: COVID-19 Deaths by Race and Ethnicity in the U.S. Retrieved November 27, 2020, from https://www.apmresearchlab.org/covid/deaths-by-race

Blevins, C. A., Weathers, F. W., Davis, M. T., Witte, T. K., \& Domino, J. L. (2015). The Posttraumatic Stress Disorder Checklist for DSM-5 (PCL-5): Development and Initial Psychometric Evaluation. Journal of Traumatic Stress, 28(6), 489-498.

\section{https://doi.org/10.1002/jts.22059}

Bovin, M. J., Marx, B. P., Weathers, F. W., Gallagher, M. W., Rodriguez, P., Schnurr, P. P., \& Keane, T. M. (2016). Psychometric properties of the PTSD Checklist for Diagnostic and Statistical Manual of Mental Disorders-Fifth Edition (PCL-5) in veterans. Psychological Assessment, 28(11), 1379-1391. https://doi.org/10.1037/pas0000254

Brown, S. M., Doom, J. R., Lechuga-Peña, S., Watamura, S. E., \& Koppels, T. (2020). Stress and parenting during the global COVID-19 pandemic. Child Abuse \& Neglect, 110, 104699. https://doi.org/10.1016/j.chiabu.2020.104699

Center for Disease Control and Prevention. (2020). Health Equity Considerations and Racial and Ethnic Minority Groups. https://www.cdc.gov/coronavirus/2019-ncov/community/healthequity/race-ethnicity.html

Clark, E., Fredricks, K., Woc-Colburn, L., Bottazzi, M. E., \& Weatherhead, J. (2020). Disproportionate impact of the COVID-19 pandemic on immigrant communities in the 
United States. PLOS Neglected Tropical Diseases, 14(7), e0008484.

https://doi.org/10.1371/journal.pntd.0008484

Dong, E., Du, H., \& Gardner, L. (2020). An interactive web-based dashboard to track COVID-19 in real time. The Lancet Infectious Diseases, 20(5), 533-534.

https://doi.org/10.1016/s1473-3099(20)30120-1

Ehrenreich-May, J. (2020). Fear of Illness and Virus Evaluation (FIVE) [Measurement instrument].

Falgas, I., Ramos, Z., Herrera, L., Qureshi, A., Chavez, L., Bonal, C., McPeck, S., Wang, Y., Cook, B., \& Alegría, M. (2017). Barriers to and Correlates of Retention in Behavioral Health Treatment Among Latinos in 2 Different Host Countries. Journal of Public Health Management and Practice, 23(1), e20-e27. https://doi.org/10.1097/phh.0000000000000391

Fortuna, L. R., Tolou-Shams, M., Robles-Ramamurthy, B., \& Porche, M. V. (2020). Inequity and the disproportionate impact of COVID-19 on communities of color in the United States: The need for a trauma-informed social justice response. Psychological Trauma: Theory, Research, Practice, and Policy, 12(5), 443-445. https://doi.org/10.1037/tra0000889

Garcini, L. M., Domenech Rodriguez, M. M., Mercado, A., \& Paris, M. (2020). A tale of two crises: The compounded effect of COVID-19 and anti-immigration policy in the United States. Psychological Trauma: Theory, Research, Practice, and Policy, 12(S1), S230S232. https://doi.org/10.1037/tra0000775 
Gould, E., Perez, D., \& Wilson, V. (2020). Latinx workers-particularly women-face devastating job losses in the COVID-19 recession. https://www.epi.org/publication/latinx-workers-covid/

Grasso, D. J., Briggs-Gowan, M. J., Ford, J. D., \& Carter, A. S. (2020). Epidemic-Pandemic Impacts Inventory [Measurement instrument]. https://www.phenxtoolkit.org/toolkit_content/PDF/Grasso_EPII.pdf

Holingue, C., Badillo-Goicoechea, E., Riehm, K. E., Veldhuis, C. B., Thrul, J., Johnson, R. M., Fallin, M. D., Kreuter, F., Stuart, E. A., \& Kalb, L. G. (2020). Mental distress during the COVID-19 pandemic among US adults without a pre-existing mental health condition: Findings from American trend panel survey. Preventive Medicine, 139, 106231. https://doi.org/10.1016/j.ypmed.2020.106231

Huang, F. Y., Chung, H., Kroenke, K., \& Spitzer, R. L. (2006). Racial and Ethnic Differences in the Relationship Between Depression Severity and Functional Status. Psychiatric Services, 57(4), 498-503. https://doi.org/10.1176/ps.2006.57.4.498

Kroenke, K., Spitzer, R. L., \& Williams, J. B. W. (2001). The PHQ-9. Journal of General Internal Medicine, 16(9), 606-613. https://doi.org/10.1046/j.15251497.2001.016009606.x

Krogstad, J. M., Gonzalez-Barrera, A., \& Noe-Bustamante, L. (2020). U.S. Latinos Among Hardest Hit by Pay Cuts, Job Losses Due to Coronavirus. Pew Research Center. https://www.pewresearch.org/fact-tank/2020/04/03/u-s-latinos-among-hardest-hit-bypay-cuts-job-losses-due-to-coronavirus/

Liu, C. H., Zhang, E., Wong, G. T. F., Hyun, S., \& Hahm, H. C. (2020). Factors associated with depression, anxiety, and PTSD symptomatology during the COVID-19 pandemic: 
Clinical implications for U.S. young adult mental health. Psychiatry Research, 290, 113172. https://doi.org/10.1016/j.psychres.2020.113172

Liu, N., Zhang, F., Wei, C., Jia, Y., Shang, Z., Sun, L., Wu, L., Sun, Z., Zhou, Y., Wang, Y., \& Liu, W. (2020). Prevalence and predictors of PTSS during COVID-19 outbreak in China hardest-hit areas: Gender differences matter. Psychiatry Research, 287, 112921. https://doi.org/10.1016/j.psychres.2020.112921

Lund, E. M. (2020). Even more to handle: Additional sources of stress and trauma for clients from marginalized racial and ethnic groups in the United States during the COVID-19 pandemic. Counselling Psychology Quarterly, 1-10.

$\underline{\text { https://doi.org/10.1080/09515070.2020.1766420 }}$

McGinty, E. E., Presskreischer, R., Han, H., \& Barry, C. L. (2020). Psychological Distress and Loneliness Reported by US Adults in 2018 and April 2020. JAMA, 324(1), 93.

\section{https://doi.org/10.1001/jama.2020.9740}

Merz, E. L., Malcarne, V. L., Roesch, S. C., Riley, N., \& Sadler, G. R. (2011). A multigroup confirmatory factor analysis of the Patient Health Questionnaire-9 among English- and Spanish-speaking Latinas. Cultural Diversity and Ethnic Minority Psychology, 17(3), 309-316. https://doi.org/10.1037/a0023883

Mills, S. D., Fox, R. S., Malcarne, V. L., Roesch, S. C., Champagne, B. R., \& Sadler, G. R. (2014). The psychometric properties of the generalized anxiety disorder-7 scale in Hispanic Americans with English or Spanish language preference. Cultural Diversity and Ethnic Minority Psychology, 20(3), 463-468. https://doi.org/10.1037/a0036523 
Spitzer, R. L., Kroenke, K., Williams, J. B. W., \& Löwe, B. (2006). A Brief Measure for Assessing Generalized Anxiety Disorder. Archives of Internal Medicine, 166(10), 1092. https://doi.org/10.1001/archinte.166.10.1092

Thakur, N., Lovinsky-Desir, S., Bime, C., Wisnivesky, J. P., \& Celedon, J. C. (2020). The Structural and Social Determinants of the Racial/Ethnic Disparities in the U.S. COVID19 Pandemic. What's Our Role? American Journal of Respiratory and Critical Care Medicine, 202(7), 943-949. https://doi.org/10.1164/rccm.202005-1523PP

Tull, M. T., Edmonds, K. A., Scamaldo, K. M., Richmond, J. R., Rose, J. P., \& Gratz, K. L. (2020). Psychological Outcomes Associated with Stay-at-Home Orders and the Perceived Impact of COVID-19 on Daily Life. Psychiatry Research, 289, 113098. https://doi.org/10.1016/j.psychres.2020.113098

Twenge, J. M., \& Joiner, T. E. (2020). Mental distress among U.S. adults during the COVID-19 pandemic. Journal of Clinical Psychology. https://doi.org/10.1002/jclp.23064

Velasco-Mondragon, E., Jimenez, A., Palladino-Davis, A. G., Davis, D., \& Escamilla-Cejudo, J. A. (2016). Hispanic health in the USA: a scoping review of the literature. Public Health Reviews, 37(1). https://doi.org/10.1186/s40985-016-0043-2

Weathers, F. W., Litz, B. T., Keane, T. M., Palmieri, P. A., Marx, B. P., \& Schnurr, P. P. (2013). The PTSD Checklist for DSM-5 (PCL-5) - Standard [Measurement instrument]. https://www.ptsd.va.gov/ 
Table 1

Participant Demographic Characteristics

\begin{tabular}{|c|c|c|}
\hline \multirow[b]{2}{*}{ Variable } & \multicolumn{2}{|c|}{$N=388$} \\
\hline & $n(\%)$ & $M(S D)$ \\
\hline \multicolumn{3}{|l|}{ Gender } \\
\hline Female & $315(81.2)$ & \\
\hline Male & $62(16.0)$ & \\
\hline Gender non-conforming/Non-binary & $8(2.1)$ & \\
\hline Transgender Female & $3(0.8)$ & \\
\hline Age, in years & & $28.52(11.09)$ \\
\hline \multicolumn{3}{|l|}{ Primary language } \\
\hline English & $304(78.4)$ & \\
\hline Spanish & $80(20.6)$ & \\
\hline Other (English \& Spanish equally) & $4(1.0)$ & \\
\hline \multicolumn{3}{|l|}{ Race } \\
\hline White & $282(72.7)$ & \\
\hline Black or African-American & $4(1.0)$ & \\
\hline American Indian/Alaska Native & $3(0.8)$ & \\
\hline Asian & $1(0.3)$ & \\
\hline Other & $5(1.3)$ & \\
\hline Multiracial & $13(3.4)$ & \\
\hline Unknown & $80(20.6)$ & \\
\hline \multicolumn{3}{|l|}{ Birth country } \\
\hline United States & $324(83.7)$ & \\
\hline Mexico & $48(12.4)$ & \\
\hline South America & $5(1.3)$ & \\
\hline Puerto Rico & $4(1.0)$ & \\
\hline Spain & $1(0.3)$ & \\
\hline Cuba & $1(0.3)$ & \\
\hline Other country, unknown & $4(1.0)$ & \\
\hline If foreign-born, years lived in the United States & & $19.72(12.99)$ \\
\hline \multicolumn{3}{|l|}{ Marital status } \\
\hline Single & $248(63.9)$ & \\
\hline Married & $90(23.2)$ & \\
\hline Living with partner & $25(6.4)$ & \\
\hline Divorced, widowed, separated & $25(6.4)$ & \\
\hline \multicolumn{3}{|l|}{ Education } \\
\hline Some high school & $1(0.3)$ & \\
\hline High school or GED & $60(15.5)$ & \\
\hline
\end{tabular}




\begin{tabular}{|c|c|c|}
\hline \multirow[b]{2}{*}{ Variable } & \multicolumn{2}{|c|}{$N=388$} \\
\hline & $n(\%)$ & $M(S D)$ \\
\hline Technical training/certificate & $10(2.6)$ & \\
\hline Some college & $88(22.7)$ & \\
\hline Associate's degree & $68(17.5)$ & \\
\hline Bachelor's degree & $96(24.7)$ & \\
\hline Master's degree & $48(12.4)$ & \\
\hline Doctoral/Professional degree & $17(4.4)$ & \\
\hline \multicolumn{3}{|l|}{ Employment status } \\
\hline Full-time & $135(34.8)$ & \\
\hline Part-time & $32(8.2)$ & \\
\hline Student & $166(42.8)$ & \\
\hline Not working (homemaker, unemployed, disabled) & $38(9.7)$ & \\
\hline Furloughed or laid off & $17(4.4)$ & \\
\hline Essential worker in the home & $250(65.4)$ & \\
\hline Person vulnerable to COVID-19 in the home & $222(57.7)$ & \\
\hline \multicolumn{3}{|l|}{ Income } \\
\hline$<\$ 40,000$ & $165(44.0)$ & \\
\hline$\$ 40,0000-80,0000$ & $126(33.6)$ & \\
\hline$>\$ 80,000$ & $84(22.4)$ & \\
\hline Insured & $256(66.3)$ & \\
\hline Number of people in household (Range $=1-9$ ) & & $3.78(1.52)$ \\
\hline
\end{tabular}


Table 2

Mean Scores, Standard Deviations, and Range of Scores on Measures

\begin{tabular}{lccc}
\hline \multicolumn{1}{c}{ Measure } & $M(S D)$ & Range & $n(\%)$ \\
\hline GAD-7 & $9.77(6.84)$ & $0-21$ & \\
None / Minimal (score 0-8) & & & $90(26.5)$ \\
Mild (score 5-9) & & & $84(24.7)$ \\
Moderate (score 10-14) & $10.23(7.66)$ & $0-27$ & $92(27.8)$ \\
Severe (score 15-21) & & & $92(27.3)$ \\
PHQ-9 & & & $84(24.9)$ \\
None / Minimal (score 0-8) & & & $72(21.4)$ \\
Mild (score 5-9) & & & $35(10.1)$ \\
Moderate (score 10-14) & & & $54(16.0)$ \\
Moderately Severe (score 15-19) & $19.96(17.30)$ & $0-71$ & \\
Severe (score 20-27) & & & $244(73.9)$ \\
PCL-5 & & & $86(26.1)$ \\
Subclinical symptoms (score $<31)$ & & & \\
PTSD provisional diagnosis (score $\geq 31)$ & & & \\
FIVE & $23.42(7.18)$ & $9-36$ & \\
Contamination/Illness & $22.37(8.09)$ & $10-40$ & \\
Social Distancing & $40.16(6.86)$ & $23-56$ & \\
Behaviors & $4.91(2.18)$ & $2-8$ & \\
Impact & $50.61(15.27)$ & $21-84$ & \\
Composite & & & \\
EPII & $3.60(2.18)$ & $0-11$ & \\
Work/Employment & $0.79(0.71)$ & $0-2$ & \\
Education/Training & $2.00(2.10)$ & $0-13$ & \\
Home Life & $5.61(2.10)$ & $0-10$ & \\
Social Activities & $0.62(0.91)$ & $0-5$ & \\
Economic Impact & $3.48(1.81)$ & $0-8$ & \\
Emotional Wellness/Well-being & $3.17(1.52)$ & $0-7$ & \\
Physical Health & $2.36(1.84)$ & $0-8$ & \\
Physical Distancing/Quarantine & $0.63(0.91)$ & $0-4$ & \\
Infection History & $8.69(3.79)$ & $0-18$ & \\
Positive Change & $22.03(8.50)$ & $0-43$ & \\
Negative Impacts & & & \\
\hline
\end{tabular}

Note. GAD-7 = Generalized Anxiety Disorder Scale, PHQ-9 = Patient Health Questionnaire, PCL-5 $=$ PTSD Checklist, FIVE $=$ Fear of Illness and Virus Evaluation, EPII $=$ Epidemic Pandemic Impacts Inventory. 
Table 3

Frequencies and Percentages of Common Negative and Positive Impacts Regarding COVID-19

\begin{tabular}{|c|c|}
\hline EPII Impacts & $\mathrm{n}(\%)$ \\
\hline \multicolumn{2}{|l|}{ Negative } \\
\hline Spent more time on screens and devices & $330(90.2)$ \\
\hline More time sitting down or being sedentary & $328(89.6)$ \\
\hline Family celebrations cancelled or restricted & $324(88.5)$ \\
\hline Unable to do enjoyable activities or hobbies & $304(83.1)$ \\
\hline Planned travel or vacations cancelled & $291(79.5)$ \\
\hline Separated from family/close friends & $285(77.9)$ \\
\hline Increase in sleep problems or poor sleep quality & $271(74.0)$ \\
\hline Increase in mental health problems or symptoms & $267(73.0)$ \\
\hline Less physical activity or exercise & $263(71.9)$ \\
\hline Overeating or eating more unhealthy foods & $254(69.4)$ \\
\hline Unable to participate in social clubs, sports teams, or usual volunteer activities & $255(69.7)$ \\
\hline $\begin{array}{l}\text { Spent a lot of time disinfecting at home due to close contact with people who } \\
\text { might be infected at work }\end{array}$ & $232(63.4)$ \\
\hline $\begin{array}{l}\text { Had to continue to work even though in close contact with people who might } \\
\text { be infected }\end{array}$ & $215(58.7)$ \\
\hline Religious or spiritual activities cancelled or restricted & $208(56.8)$ \\
\hline Increase in workload or work responsibilities & $201(54.9)$ \\
\hline Isolated or quarantined due to possible exposure to this disease & $196(53.6)$ \\
\hline Had a child in home who could not go to school & $177(48.4)$ \\
\hline Limited physical closeness with child or loved one due to concerns of infection & $168(45.9)$ \\
\hline Reduced work hours or furloughed & $162(44.3)$ \\
\hline $\begin{array}{l}\text { Isolated due to existing health conditions that increase risk of infection or } \\
\text { disease }\end{array}$ & $148(40.4)$ \\
\hline Hard time making the transition to working from home & $144(39.3)$ \\
\hline Entire house was quarantined for a week or longer & $130(35.5)$ \\
\hline \multicolumn{2}{|l|}{ Positive } \\
\hline More appreciative of things usually taken for granted & $297(81.1)$ \\
\hline Paid more attention to personal health & $276(75.4)$ \\
\hline More quality time with family/friends in person or from a distance & $264(72.1)$ \\
\hline More time doing enjoyable activities & $241(65.8)$ \\
\hline Paid more attention to preventing physical injuries & $201(54.9)$ \\
\hline Developed new hobbies or activities & $201(54.9)$ \\
\hline Improved relationships with family/friends & $201(54.9)$ \\
\hline Ate healthier foods & $188(51.4)$ \\
\hline Found greater meaning in work, employment, or school & $187(51.1)$ \\
\hline
\end{tabular}

Note. $N=366$; endorsement of negative impacts and positive changes due to COVID-19 are not mutually exclusive. EPII = Epidemic Pandemic Impacts Inventory. 


\section{Table 4}

Mental Health Mean Scores by Demographic Characteristics

\begin{tabular}{|c|c|c|c|}
\hline Characteristic & GAD-7 & PHQ-9 & PCL-5 \\
\hline \multicolumn{4}{|l|}{ Gender } \\
\hline Female & $10.29(6.75)^{\mathrm{a}}$ & $10.75(7.66)^{\mathrm{a}}$ & $21.25(17.57)^{\mathrm{a}}$ \\
\hline Male & $6.86(6.82)^{\mathrm{b} * *}$ & $7.02(6.77)^{b * *}$ & $13.04(14.93)^{\mathrm{b} * *}$ \\
\hline \multicolumn{4}{|l|}{ Primary language } \\
\hline English & $9.55(6.83)$ & $9.71(7.57)^{\mathrm{a}}$ & $18.77(16.15)^{\mathrm{a}}$ \\
\hline Spanish & $10.59(6.84)$ & $12.30(7.61)^{\mathrm{b} *}$ & $24.64(20.43)^{\mathrm{b} *}$ \\
\hline \multicolumn{4}{|l|}{ Nativity } \\
\hline U.S-born & $10.05(6.91)$ & $10.52(7.79)$ & $20.59(17.42)$ \\
\hline Foreign-born & $8.25(6.27)$ & $8.59(6.70)$ & $16.49(16.40)$ \\
\hline \multicolumn{4}{|l|}{ Marital status } \\
\hline Single & $10.38(6.94)$ & $11.85(7.89)^{\mathrm{a}}$ & $21.33(17.27)^{\mathrm{a}}$ \\
\hline Married or living with partner & $8.43(6.41)$ & $7.12(6.12)^{\mathrm{b} * * *}$ & $16.25(15.62)^{\mathrm{b} *}$ \\
\hline Divorced, widowed, separated & $10.21(7.15)$ & $9.58(7.52)$ & $24.04(22.00)$ \\
\hline \multicolumn{4}{|l|}{ Education } \\
\hline Less than college & $10.25(7.04)^{\mathrm{b} *}$ & $11.28(7.77)^{\mathrm{b} * * *}$ & $20.85(16.80)^{\mathrm{b} * *}$ \\
\hline College degree & $10.29(6.53)^{\mathrm{b} *}$ & $10.64(7.55)^{\mathrm{b} * *}$ & $22.04(17.84)^{\mathrm{b} * *}$ \\
\hline Graduate school & $7.25(6.64)^{\mathrm{a}}$ & $6.61(6.63)^{\mathrm{a}}$ & $12.49(15.34)^{\mathrm{a}}$ \\
\hline \multicolumn{4}{|l|}{ Employment status } \\
\hline Full-time & $8.73(6.52)$ & $7.83(7.07)^{\mathrm{a}}$ & $16.63(16.92)$ \\
\hline Part-time & $10.07(7.21)$ & $8.55(7.02)$ & $14.71(11.76)$ \\
\hline Student & $10.15(6.67)$ & $12.00(7.55)^{\mathrm{b} * * *}$ & $22.21(17.39)$ \\
\hline Not working & $11.00(7.68)$ & $11.81(8.12)^{\mathrm{b} *}$ & $24.40(18.90)$ \\
\hline \multicolumn{4}{|l|}{ Essential worker in the home } \\
\hline No & $8.31(6.56)^{\mathrm{a}}$ & $8.71(6.94)^{\mathrm{a}}$ & $16.78(16.25)^{\mathrm{a}}$ \\
\hline Yes & $10.51(6.92)^{\mathrm{b} * *}$ & $11.00(7.89)^{\mathrm{b} * *}$ & $21.76(17.70)^{\mathrm{b} *}$ \\
\hline \multicolumn{4}{|l|}{ Vulnerable person in the home } \\
\hline No & $8.65(6.98)^{\mathrm{a}}$ & $9.23(7.86)^{\mathrm{a}}$ & $17.13(16.78)^{\mathrm{a}}$ \\
\hline Yes & $10.62(6.65)^{\mathrm{b} * *}$ & $10.91(7.37)^{\mathrm{b} *}$ & $21.90(17.20)^{\mathrm{b} *}$ \\
\hline \multicolumn{4}{|l|}{ Income } \\
\hline$<\$ 40,000$ & $10.35(6.82)^{\mathrm{b} *}$ & $11.92(7.91)^{\mathrm{b} * * *}$ & $22.07(18.08)^{\mathrm{a}}$ \\
\hline$\$ 40,0000-80,0000$ & $10.07(6.73)^{\mathrm{b} *}$ & $10.02(7.23)^{\mathrm{b} *}$ & $19.33(16.31)$ \\
\hline$>\$ 80,000$ & $7.64(6.48)^{\mathrm{a}}$ & $7.01(6.52)^{\mathrm{a}}$ & $15.10(15.16)^{\mathrm{b} *}$ \\
\hline \multicolumn{4}{|l|}{ Health insurance } \\
\hline No & $10.58(6.87)$ & $12.34(7.66)^{\mathrm{a}}$ & $22.18(18.02)$ \\
\hline Yes & $9.31(6.77)$ & $9.15(7.43)^{\mathrm{b} * * *}$ & $18.68(16.75)$ \\
\hline
\end{tabular}


Note. Subscripts indicate significant differences between groups. GAD-7 = Generalized Anxiety Disorder Scale, PHQ-9 = Patient Health Questionnaire, PCL-5 = PTSD Checklist. ${ }^{*} p<.05,{ }^{* *} p<.01,{ }^{* * *} p<.001$. 


\section{Table 5}

Fear of Illness and Virus Evaluation Subscales and Composite Mean Scores by Demographic Characteristics

\begin{tabular}{|c|c|c|c|c|c|}
\hline Characteristic & $\begin{array}{c}\text { Fears of } \\
\text { Contamination } \\
\text { and Illness }\end{array}$ & $\begin{array}{l}\text { Fears of Social } \\
\text { Distancing }\end{array}$ & Behaviors & Impact & Composite Score \\
\hline \multicolumn{6}{|l|}{ Gender } \\
\hline Female & $24.01(7.03)^{\mathrm{a}}$ & $22.87(8.02)^{\mathrm{a}}$ & $40.87(6.59)^{\mathrm{a}}$ & $5.06(2.19)^{\mathrm{a}}$ & $51.84(14.97)^{\mathrm{a}}$ \\
\hline Male & $20.74(7.42)^{\mathrm{b} * *}$ & $20.09(8.28)^{\mathrm{b} *}$ & $37.33(7.23)^{\mathrm{b} * * *}$ & $4.14(1.93)^{\mathrm{b} * *}$ & $44.93(15.85)^{b * *}$ \\
\hline \multicolumn{6}{|l|}{ Primary language } \\
\hline English & $23.24(7.26)$ & $22.18(8.07)$ & $40.07(6.73)$ & $4.87(2.15)$ & $50.18(15.26)$ \\
\hline Spanish & $24.49(6.80)$ & $23.31(8.20)$ & $40.39(7.33)$ & $5.09(2.27)$ & $52.89(15.22)$ \\
\hline \multicolumn{6}{|l|}{ Nativity } \\
\hline U.S-born & $23.73(7.15)^{\mathrm{a}}$ & $22.70(8.01)$ & $40.28(6.75)$ & $5.04(2.18)^{\mathrm{a}}$ & $51.18(15.17)^{\mathrm{a}}$ \\
\hline Foreign-born & $21.60(7.16)^{\mathrm{b} *}$ & $20.52(8.38)$ & $39.50(7.50)$ & $4.17(2.04)^{\mathrm{b} * *}$ & $46.08(15.18)^{b *}$ \\
\hline \multicolumn{6}{|l|}{ Marital status } \\
\hline Single & $23.93(7.14)$ & $23.37(8.16)^{\mathrm{a}}$ & $40.31(6.90)$ & $5.06(2.17)$ & $52.27(15.23)^{\mathrm{a}}$ \\
\hline Married or living with partner & $22.30(6.96)$ & $20.42(7.81)^{\mathrm{b} * *}$ & $39.83(6.59)$ & $4.52(2.14)$ & $47.25(14.95)^{b *}$ \\
\hline Divorced, widowed, separated & $23.72(8.12)$ & $22.00(7.37)$ & $40.29(7.84)$ & $5.25(2.31)$ & $50.58(15.19)$ \\
\hline \multicolumn{6}{|l|}{ Education } \\
\hline Less than college & $23.78(7.67)^{\mathrm{b} *}$ & $22.59(8.24)^{\mathrm{b} * *}$ & $39.49(7.08)$ & $5.06(2.01)^{\mathrm{b} *}$ & $51.21(15.50)^{\mathrm{b} * *}$ \\
\hline College degree & $24.07(6.97)^{b * *}$ & $23.51(7.95)^{\mathrm{b} * *}$ & $40.89(6.69)$ & $5.04(2.27)^{\mathrm{b} *}$ & $52.60(15.12)^{\mathrm{b} * * *}$ \\
\hline Graduate school & $20.81(5.85)^{\mathrm{a}}$ & $18.84(7.17)^{\mathrm{a}}$ & $39.91(6.67)$ & $4.18(2.20)^{\mathrm{a}}$ & $43.89(13.36)^{\mathrm{a}}$ \\
\hline \multicolumn{6}{|l|}{ Employment status } \\
\hline Full-time & $23.24(6.92)$ & $21.30(7.83)$ & $40.59(6.78)$ & $4.71(2.25)$ & $49.22(15.04)$ \\
\hline Part-time & $22.43(6.77)$ & $22.50(8.25)$ & $40.10(6.34)$ & $4.97(2.03)$ & $49.90(14.52)$ \\
\hline Student & $23.30(7.20)$ & $22.75(8.38)$ & $39.86(6.92)$ & $5.10(2.08)$ & $50.99(15.47)$ \\
\hline Not working & $24.78(7.95)$ & $23.77(7.65)$ & $40.06(7.33)$ & $4.77(2.37)$ & $53.31(15.74)$ \\
\hline \multicolumn{6}{|l|}{ Essential worker in the home } \\
\hline No & $22.94(7.22)$ & $21.71(8.10)$ & $39.82(7.06)$ & $4.94(2.16)$ & $49.51(15.11)$ \\
\hline Yes & $23.58(7.19)$ & $22.71(8.08)$ & $40.36(6.81)$ & $4.85(2.18)$ & $51.06(15.40)$ \\
\hline Vulnerable person in the home & & & & & \\
\hline
\end{tabular}




\begin{tabular}{|c|c|c|c|c|c|}
\hline Characteristic & $\begin{array}{c}\text { Fears of } \\
\text { Contamination } \\
\text { and Illness }\end{array}$ & $\begin{array}{l}\text { Fears of Social } \\
\text { Distancing }\end{array}$ & Behaviors & Impact & Composite Score \\
\hline No & $21.71(7.29)^{\mathrm{a}}$ & $20.71(7.73)^{\mathrm{a}}$ & $39.68(6.71)$ & $4.50(2.18)^{\mathrm{a}}$ & $46.86(14.94)^{\mathrm{a}}$ \\
\hline Yes & $24.62(6.81)^{\mathrm{b} * * *}$ & $23.56(8.11)^{\mathrm{b} * *}$ & $40.52(6.94)$ & $5.19(2.12)^{b * *}$ & $53.25(14.89)^{\mathrm{b} * * *}$ \\
\hline \multicolumn{6}{|l|}{ Income } \\
\hline$<\$ 40,000$ & $24.23(7.32)$ & $23.30(8.07)^{\mathrm{b} * * *}$ & $40.24(7.12)$ & $5.14(2.17)^{\mathrm{a}}$ & $52.64(15.47)^{\mathrm{a}}$ \\
\hline$\$ 40,0000-80,0000$ & $23.13(7.18)$ & $22.94(8.57)^{\mathrm{b} * *}$ & $40.05(6.48)$ & $4.95(2.22)$ & $50.93(15.88)$ \\
\hline$>\$ 80,000$ & $22.03(6.84)$ & $19.19(6.89)^{\mathrm{a}}$ & $40.11(7.00)$ & $4.29(2.05)^{\mathrm{b} *}$ & $45.33(13.14)^{\mathrm{b} * *}$ \\
\hline \multicolumn{6}{|l|}{ Health insurance } \\
\hline No & $23.88(7.65)$ & $24.67(8.10)^{\mathrm{a}}$ & $40.02(7.36)$ & $5.03(2.20)$ & $53.46(15.75)^{\mathrm{a}}$ \\
\hline Yes & $23.10(6.90)$ & $21.22(7.87)^{\mathrm{b} * * *}$ & $40.24(6.64)$ & $4.82(2.16)$ & $49.08(14.80)^{\mathrm{b} *}$ \\
\hline
\end{tabular}

Note. Subscripts indicate significant differences between groups.

$* p<.05, * * p<.01, * * * p<.001$. 


\section{Table 6}

Negative and Positive Impact Counts by Demographic Characteristics

\begin{tabular}{|c|c|c|}
\hline Characteristic & Negative & Positive \\
\hline \multicolumn{3}{|l|}{ Gender } \\
\hline Female & $22.79(8.45)^{\mathrm{a}}$ & $8.55(3.61)^{\mathrm{a}}$ \\
\hline Male & $18.10(7.98)^{\mathrm{b} * * *}$ & $9.79(4.27)^{\mathrm{b} *}$ \\
\hline \multicolumn{3}{|l|}{ Primary language } \\
\hline English & $21.80(8.68)$ & $8.70(3.84)$ \\
\hline Spanish & $22.79(7.83)$ & $8.62(3.54)$ \\
\hline \multicolumn{3}{|l|}{ Nativity } \\
\hline U.S-born & $22.46(8.65)^{\mathrm{a}}$ & $8.64(3.88)$ \\
\hline Foreign-born & $19.75(7.41)^{\mathrm{b} *}$ & $8.90(3.36)$ \\
\hline \multicolumn{3}{|l|}{ Marital status } \\
\hline Single & $22.31(8.56)$ & $8.51(3.81)$ \\
\hline Married or living with partner & $21.19(8.68)$ & $9.06(3.88)$ \\
\hline Divorced, widowed, separated & $23.12(9.02)$ & $8.60(3.22)$ \\
\hline \multicolumn{3}{|l|}{ Education } \\
\hline Less than college & $22.28(8.50)^{\mathrm{b} * *}$ & $8.39(3.87)$ \\
\hline College degree & $23.18(8.55)^{\mathrm{b} * * *}$ & $8.88(3.74)$ \\
\hline Graduate school & $18.55(7.52)^{\mathrm{a}}$ & $8.92(3.73)$ \\
\hline \multicolumn{3}{|l|}{ Employment status } \\
\hline Full-time & $20.48(8.28)$ & $8.96(3.62)$ \\
\hline Part-time & $23.29(8.73)$ & $8.53(3.77)$ \\
\hline Student & $22.43(8.29)$ & $8.49(3.77)$ \\
\hline Not working & $23.96(9.11)$ & $8.69(4.30)$ \\
\hline \multicolumn{3}{|l|}{ Essential worker in the home } \\
\hline No & $19.75(7.42)^{\mathrm{a}}$ & $8.72(3.63)$ \\
\hline Yes & $23.25(8.87)^{\mathrm{b} * * *}$ & $8.75(3.87)$ \\
\hline \multicolumn{3}{|l|}{ Vulnerable person in the home } \\
\hline No & $20.00(8.59)^{\mathrm{a}}$ & $8.66(3.63)$ \\
\hline Yes & $23.50(8.18)^{\mathrm{b} * * *}$ & $8.68(3.91)$ \\
\hline \multicolumn{3}{|l|}{ Income } \\
\hline$<\$ 40,000$ & $22.42(8.76)$ & $8.38(3.79)$ \\
\hline$\$ 40,0000-80,0000$ & $21.66(7.80)$ & $8.76(3.61)$ \\
\hline$>\$ 80,000$ & $21.54(8.68)$ & $9.56(3.85)$ \\
\hline \multicolumn{3}{|l|}{ Health insurance } \\
\hline No & $23.48(8.15)^{\mathrm{a}}$ & $8.30(3.84)$ \\
\hline Yes & $21.25(8.58)^{\mathrm{b} *}$ & $8.89(3.75)$ \\
\hline
\end{tabular}

Note. Subscripts indicate significant differences between groups. 
${ }^{*} p<.05, * * p<.01, * * * p<.001$. 


\section{Supplementary Table 1}

Bivariate and Point-biserial Correlations Between Demographic Characteristics and Mental Health Measures

\begin{tabular}{|c|c|c|c|c|c|c|c|c|c|}
\hline Variable & 1 & 2 & 3 & 4 & 5 & 6 & 7 & 8 & 9 \\
\hline 1. Gender & - & & & & & & & & \\
\hline 2. Language & -.04 & - & & & & & & & \\
\hline 3. Nativity & .05 & $.34 * * *$ & - & & & & & & \\
\hline 4. Marital Status & .00 & .04 & -.07 & - & & & & & \\
\hline 5. Education & .08 & .10 & -.04 & $.34 * * *$ & - & & & & \\
\hline 6. Essential & .01 & -.03 & .04 & -.02 & -.05 & - & & & \\
\hline 7. Vulnerable & -.01 & .02 & .08 & $-.12 *$ & -.06 & $.13^{*}$ & - & & \\
\hline 8. Income & -.08 & $.16^{* *}$ & -.04 & $.36 * * *$ & $.29 * * *$ & .06 & -.09 & - & \\
\hline 9. Insurance & .04 & $.14 * *$ & .09 & $.25 * * *$ & $.22 * * *$ & -.01 & -.07 & $.26 * * *$ & - \\
\hline 10. GAD-7 & $.19 * *$ & -.06 & .10 & $-.13 *$ & -.11 & $.15^{* *}$ & $.14 * *$ & $-.12 *$ & -.09 \\
\hline 11. PHQ-9 & $.18 * *$ & $-.14^{*}$ & .09 & $-.27 * * *$ & $-.21 * * *$ & $.14^{* *}$ & $.11 *$ & $-.22 * * *$ & $-.19 * * *$ \\
\hline 12. PCL-5 & $.18 * *$ & $-.14 *$ & .09 & $-.14 * *$ & $-.11 *$ & $.14^{*}$ & $.14^{*}$ & $-.14^{*}$ & -.10 \\
\hline 13. FIVE - Contamination & $.17 * *$ & -.07 & $.11 *$ & -.10 & -.09 & .04 & $.20 * * *$ & $-.12 *$ & -.05 \\
\hline 14. FIVE - Social Distancing & $.13 *$ & -.06 & .10 & $-.16 * *$ & -.11 & .06 & $.18 * *$ & $-.21 * * *$ & $-.20 * * *$ \\
\hline 15. FIVE - Behaviors & $.20 * * *$ & -.02 & .04 & -.03 & .09 & .04 & .06 & .03 & .02 \\
\hline 16. FIVE - Impact & $.16^{* *}$ & -.04 & $.14 * *$ & $-.12 *$ & -.07 & -.02 & $.16^{* *}$ & $-.13 *$ & -.04 \\
\hline 17. FIVE - Composite & $.17 * *$ & -.07 & $.13 *$ & $-.15^{*}$ & -.10 & .05 & $.21 * * *$ & $-.19 * *$ & $-.14^{*}$ \\
\hline 18. EPII - Positive Change & $-.12 *$ & .01 & -.03 & .07 & .08 & .00 & .00 & $.11 *$ & .07 \\
\hline 19. EPII - Negative Impacts & $.20 * * *$ & -.05 & $.12 *$ & -.07 & -.08 & $.20 * * *$ & $.20 * * *$ & -.02 & $-.12 *$ \\
\hline
\end{tabular}

Note. Essential $=$ Essential worker in the home. Vulnerable $=$ Person vulnerable to COVID in the home. GAD-7 = Generalized

Anxiety Disorder Scale, PHQ-9 = Patient Health Questionnaire, PCL-5 = PTSD Checklist, FIVE = Fear of Illness and Virus

Evaluation, EPII = Epidemic Pandemic Impacts Inventory. Gender is coded $0=$ male, $1=$ female. Language is coded $0=$ Spanish, $1=$ English. Nativity is coded $0=$ foreign-born, $1=\mathrm{U} . \mathrm{S}$. -born. Marital status is coded $0=$ single/divorced/widowed/separated,

$1=$ married/living with partner. Essential worker is coded $0=$ no, $1=$ yes. Vulnerable is coded $0=$ no, $1=$ yes. Insurance is coded $0=$ no, $1=$ yes.

$* p<.05, * * p<.01, * * * p<.001$. 


\section{Supplementary Table 1 continued.}

Bivariate and Point-biserial Correlations Between Demographic Variables and Mental Health Measures

\begin{tabular}{|c|c|c|c|c|c|c|c|c|c|}
\hline Variable & 10 & 11 & 12 & 13 & 14 & 15 & 16 & 17 & 18 \\
\hline \multicolumn{10}{|l|}{ 1. Gender } \\
\hline \multicolumn{10}{|l|}{ 2. Language } \\
\hline \multicolumn{10}{|l|}{ 3. Nativity } \\
\hline \multicolumn{10}{|l|}{ 4. Marital Status } \\
\hline \multicolumn{10}{|l|}{ 5. Education } \\
\hline \multicolumn{10}{|l|}{ 6. Essential } \\
\hline \multicolumn{10}{|l|}{ 7. Vulnerable } \\
\hline \multicolumn{10}{|l|}{ 8. Income } \\
\hline \multicolumn{10}{|l|}{ 9. Insurance } \\
\hline 10. GAD-7 & - & & & & & & & & \\
\hline 11. PHQ-9 & $.74 * * *$ & - & & & & & & & \\
\hline 12. PCL-5 & $.77 * * *$ & $.76 * * *$ & - & & & & & & \\
\hline 13. FIVE - Contamination & $.49 * * *$ & $.35 * * *$ & $.50 * * *$ & - & & & & & \\
\hline 14. FIVE - Social Distancing & $.53 * * *$ & $.46^{* * *}$ & $.55 * * *$ & $.65 * * *$ & - & & & & \\
\hline 15. FIVE - Behaviors & $.25 * * *$ & $.12 *$ & $.26 * * *$ & $.40 * * *$ & $.28 * * *$ & - & & & \\
\hline 16. FIVE - Impact & $.66 * * *$ & $.49 * * *$ & $.61 * * *$ & $.56 * * *$ & $.55 * * *$ & $.30 * * *$ & - & & \\
\hline 17. FIVE - Composite & $.60 * * *$ & $.48 * * *$ & $.61 * * *$ & $.89 * * *$ & $.91 * * *$ & $.36^{* * *}$ & $.70 * * *$ & - & \\
\hline 18. EPII - Positive Change & -.09 & $-.22 * * *$ & -.02 & $.15^{* *}$ & .05 & $.25 * * *$ & .03 & $.18 * *$ & - \\
\hline 19. EPII - Negative Impacts & $.49 * * *$ & $.45 * * *$ & $.56 * * *$ & $.31 * * *$ & $.35 * * *$ & $.25 * * *$ & $.36^{* * *}$ & $.38 * * *$ & .09 \\
\hline
\end{tabular}

Note. Essential $=$ Essential worker in the home. Vulnerable $=$ Person vulnerable to COVID in the home. GAD-7 = Generalized

Anxiety Disorder Scale, PHQ-9 = Patient Health Questionnaire, PCL-5 = PTSD Checklist, FIVE = Fear of Illness and Virus Evaluation, EPII = Epidemic Pandemic Impacts Inventory. Gender is coded $0=$ male, $1=$ female. Language is coded $0=$ Spanish, $1=$ English. Nativity is coded $0=$ foreign-born, $1=$ U.S.-born. Marital status is coded $0=$ single/divorced/widowed/separated, $1=$ married/living with partner. Essential worker is coded $0=$ no, $1=$ yes. Vulnerable is coded $0=$ no, $1=$ yes. Insurance is coded $0=$ no, $1=$ yes.

$* p<.05, * * p<.01, * * * p<.001$. 